Maestros por siempre 



\title{
En recuerdo de José León Barandiarán Hart
}

\author{
Fernando Vidal Ramírez
}

Recordar a José León Barandiarán Hart es hacer el trazo de una personalidad carismática que traslucía sencillez y que, dotada de una innata simpatía, ganaba amigos, sin proponérselo, con su pródiga cordialidad y su conversación amena y fluida. Pepe - como lo llamábamos sus amigos - fue un hombre cabal que supo, además de vivir a plenitud, afrontar con entereza la cruel y artera enfermedad que lo sustrajo de su hogar, de las aulas, de sus libros y de todo lo que amaba.

Vino al mundo en el hogar que formaron el 7 de diciembre de 1940 -al unirse en matrimonio- don José León Barandiarán y doña Rebeca Hart Rivero. Su padre, el ilustre maestro sanmarquino y jurista representativo de la última centuria, que vino de su natal Lambayeque para hacer sus estudios de derecho, quedó desde entonces vinculado consustancialmente con San Marcos como estudioso, catedrático, decano de la Facultad de Derecho y, también, rector de la universidad. Su madre fue una dama limeña de singular temple y compañera inseparable del ilustre maestro.

Pepe nació el 18 de enero de 1946, día en que se conmemora la fundación española de la ciudad de Lima, a la que años más tarde serviría como concejal. Fue el primogénito; luego vendrían Ana María y, después, Eduardo y Miguel. 
Su infancia y adolescencia transcurrieron en Lince, en la casa de la calle José de la Torre Ugarte, en la que él y sus hermanos vivieron los años de su infancia, y Pepe, hasta los primeros años de su juventud. Desde niño fue sumamente apacible, y ese fue un rasgo de su personalidad, aunque en los juegos infantiles no le gustaba perder - como recuerda su hermana Ana María-, sobre todo cuando jugaba a los carritos en el patio interior de su casa, ni tampoco cuando con sus tres hermanos jugaba allí mismo con una pelota. En esos juegos infantiles se originaría su afición por el fútbol, aunque el basquetbol fue su deporte predilecto y lo practicaría con asiduidad hasta su adultez.

En fútbol, era hincha de Universitario de Deportes - la U-, y en la tarde de los domingos concurría al Estadio Nacional desde su casa de José de la Torre Ugarte, que estaba relativamente cerca. Más tarde, su afición lo llevaría también a prestar su colaboración a la Federación Peruana de Fútbol, en la que asesoró a su amigo Luis Vargas Hornes cuando asumió la presidencia. Su relación con la federación continuó, pues siempre estuvo atento al llamado de Javier Quintana, el secretario general, para que prestara su concurso e integrara diversas comisiones, en algunas de las cuales participamos juntos.

Sus estudios escolares los inició en 1952, en el colegio Santa Margarita, en su antiguo local de San Isidro - y que entonces, como ahora, era mixto-, hasta concluirlos en 1961. Siempre destacó por su clara inteligencia y su facilidad para el aprendizaje; lo recuerdan así sus compañeros de colegio, entre quienes pueden citarse José Luis Fernandini, Javier Valdez, Manuel Pardo, Pablo Rodríguez, Julio Bayarri, Ricardo Luna; y, entre sus compañeras, Lilia Praeli, Sonia Morante, Blanca Gordillo, Miriam Barrig, Naria Esther Astete y Elisa Pancorvo. Tuvo como profesores a Miguel Ángel Cuadros, Telmo Salinas - autor de difundidos textos de lógica y ética - y Vicente Gonzales Montolivo, a quien conocí porque había sido también mi profesor de literatura, y estoy seguro de que a Pepe, como a mí, lo debe haber deleitado, pues sus clases las matizaba con la recitación de poemas de Rubén Darío y José Santos Chocano.

Conocí a Pepe cuando todavía era un colegial. Fue en una soleada tarde de diciembre de 1958, cuando yo era un estudiante de derecho en la Universidad de San Marcos y al maestro León Barandiarán - su padre - lo habían elegido rector en abril de ese año - luego de una contienda electoral sumamente reñida con Luis Alberto Sánchez, el eminente polígrafo-; doña Rebeca Hart lo había ido a visitar, acompañada 
de sus hijos, a su despacho del rectorado, y Pepe salió a jugar en los corredores de la vieja Facultad de Derecho.

Formado en el hogar del maestro León Barandiarán, Pepe no podía sustraerse al estudio de las humanidades y del derecho, y en 1962 era ya un joven estudiante sanmarquino de la Facultad de Letras de la más antigua universidad de América, en tránsito a la Facultad de Derecho.

Empezó sus estudios de derecho en 1965, año en el que tuve el privilegio de tenerlo como alumno en los inicios de mi carrera docente como profesor de Derecho Civil. Pepe era un alumno visible, pues destacaba siempre por su clara inteligencia. En su tránsito por la Facultad de Derecho tuvo como profesores a Mario Alzamora Valdez, Carlos Fernández Sessarego, Rómulo Lanatta, Jorge Eugenio Castañeda, Max Arias Schreiber, Luis Bramont Arias, Luis del Valle Rendich, Domingo García Rada, Ulises Montoya Manfredi, Luciano Castillo, Darío Herrera Paulsen, Germán Aparicio Valdez, Manuel García Calderón Koechlin, Vicente Ugarte del Pino, Guillermo García Montúfar y Andrés Aramburú Menchaca; todos ellos de una estirpe sanmarquina que se va extinguiendo y de muy grata recordación para los estudiantes sanmarquinos de aquellas y muchas otras generaciones.

A su clara inteligencia, Pepe unía su facilidad para hacerse de amigos, con muchos de los cuales ha compartido sus años de estudiante y - con algunos de ellos - su actividad profesional. En las aulas de San Marcos se reencontró con su amigo de la infancia, Hernando Montoya Alberti, hijo del maestro sanmarquino don Ulises Montoya Manfredi - amigo entrañable de don José León Barandiarán, y cuyas cónyuges, doña Carmen Alberti y doña Rebeca Hart, fueron "compañeras de barriga" al gestar simultáneamente a Hernando y a Pepe-. En las mismas aulas surgió la amistad con Luis Vargas Hornes, Luis Gonzales Posada, Alberto del Carpio, Jorge Eugenio Castañeda (hijo del maestro sanmarquino del mismo nombre), César Delgado Bachman, José de Piérola Balta, Alfredo Sayán Figari, Carmela D’Brot, Nani Nieva, Marta Sigüeñas, Manuel Portocarrero Giles, José Arenas, Luis Gonzales, Luis Lavaggi, Manuel Reátegui y José Balta Egoaguirre, entre muchos otros a quienes pido disculpas por la omisión involuntaria de sus nombres.

Pepe fue un estudiante contraído a las materias que abarcaba, pero también sabía darse tiempo para la práctica del basquetbol. Desde el inicio de sus años universitarios en el viejo gimnasio de la casona sanmarquina del parque Universitario, hizo gala de su habilidad en ese 
deporte, integrando el equipo de su promoción, al lado de José Santos Chichizola y José Merino Reyna, quienes con otros cuyos nombres se han ido de mi memoria, conformaban el quinteto de "los Pepes". Poco tiempo después, ellos integrarían el equipo representativo de San Marcos, con Simón Paredes, Carlos Valdivieso, Julio Landauro, Guillermo Arciniega y otros estudiantes de distintas facultades.

Pepe concluyó su ciclo profesional en 1969 y se recibió de abogado al año siguiente. En esa época, para obtener el título profesional era requisito haber optado previamente el grado académico de bachiller en derecho, el que le fue colacionado con la tesis "El mandato en el derecho civil peruano". Su vocación por el estudio lo condujo a continuar en la doctoral de derecho en San Marcos y a optar, en 1973, el grado académico de doctor con la tesis "El contrato de sociedad en el derecho civil peruano".

Sus trabajos de tesis merecieron de los respectivos jurados la recomendación de publicación en la revista que editaba la Facultad de Derecho sanmarquina. Pero su padre, que se aprestaba a publicar los que vendrían a ser los dos tomos de su Los contratos en el derecho civil peruano, acogió los estudios que habían dado origen a aquellas dos tesis y los instaló en sendos capítulos, reconociendo con inocultada y justificada satisfacción la autoría de su hijo.

La vocación universitaria de Pepe lo llevaría, también, a incursionar en la docencia. Su temprana presencia en las aulas como profesor le dio un bien ganado prestigio y el ofrecimiento de becas de perfeccionamiento. Así, en 1971, la Interamerican Bar Foundation lo invitó a seguir un curso de derecho angloamericano; en 1974, la Organización de los Estados Americanos lo becó para un curso de derecho internacional, en Río de Janeiro, auspiciado por el Comité Jurídico Interamericano; y en 1977, la Organización de las Naciones Unidas lo becó para un curso sobre derechos humanos.

Pepe era, además de estudioso, un lector infatigable, lo que lo dotó de una bien formada cultura que se traslucía en su fluida y amena conversación. Fue un intelectual, pero tal vez le faltó la disciplina necesaria para emprender la tarea de escribir la obra orgánica que su talento habría hecho significativa. Aunque ha dejado una obra lamentablemente dispersa en diversas revistas, su talento puede apreciarse en su trabajo sobre el derecho internacional privado, publicado en los Estudios en honor de los profesores Carlos Fernández Sessarego y Max Arias Schreiber Pezet (1986), y en su estudio "El orden público en el derecho internacional privado", publi- 
cado en el Libro homenaje a Ulises Montoya Manfredi (1989), con los que denotaba su preferencia por esta disciplina jurídica.

Su temperamento le hizo desdeñar la formalidad convencional; era un intelectual que no se sujetaba a más esquemas que los que resultaban de su visión de la vida. Y así fue siempre, incluso cuando llegó a la cúspide de su carrera docente al asumir el decanato de la Facultad de Derecho de la Universidad de Lima. La Academia Peruana de Derecho, por ejemplo, por acuerdo unánime del pleno de sus académicos, decidió invitarlo para que se incorporara como miembro de número; pero aquel desdén por la formalidad convencional, y la enfermedad que ya comenzaba a aquejarlo, privaron a la academia de tenerlo entre sus miembros.

No debe pensarse que no tomara la vida en serio, ni que evadiera las responsabilidades de su quehacer profesional. Simplemente, su temperamento lo hacía matizar sus actividades $\mathrm{y}$, así, sus tareas profesionales y su ejercicio docente no le impedían realizarse en las charlas con sus amigos o en la práctica de su deporte favorito. Pepe era sumamente reflexivo y centrado en sus opiniones; tenía, asimismo, un agudo sentido del humor.

Además del viejo gimnasio de San Marcos, el club de Regatas Lima también fue escenario de las actividades basquetbolísticas de Pepe. Participó en competiciones interclubes, nacionales e internacionales, al lado de los hermanos Ricardo, Raúl y Luis Duarte, así como de Juan Manuel de Cárdenas, Eduardo Airaldi, Bruno Ferraro, Jorge Bazo, el "Chino" Vásquez y Juan Luis Cipriani (actual arzobispo de Lima y cardenal primado del Perú). Esta práctica la mantuvo y, ya con la categoría "máster", siguió alternando con figuras representativas del Regatas y hasta alcanzó un resonante galardón, luego de una notable actuación en un torneo realizado en la ciudad de Atlanta (Estados Unidos).

Su actividad profesional la orientó, en un inicio, al sector público, prestando importantes servicios en el sector minero. Entre 1969 y 1979, con algunas intermitencias, fue abogado-asesor del despacho del ministro de Energía y Minas, jefe del Departamento de Contratos de la Dirección General de Minería, de la que fue también asesor legal, y luego asesor jurídico del ministerio. En 1982 asumió la asesoría en la Empresa Minera Comercial del Perú en materia de contratación internacional de productos mineros y, luego, hasta 1984, desempeñó una vocalía en el Consejo de Minería. 
En 1985, al llamado de su amigo y compañero de estudios Luis Gonzales Posada - que había asumido el despacho ministerial-, Pepe pasó al sector Justicia. Se desempeñó como director general de Justicia, con singular brillo. Durante su gestión, siempre evidenció su calidad, no solo profesional, sino humana, y en circunstancias de la vida profesional tuvo conmigo un gesto que lo graficó como el amigo leal que siempre fue.

Desde que se inició en la docencia universitaria, mantuvo una estrecha y creciente vinculación con la universidad, en particular San Marcos, y años más tarde con la Universidad de Lima.

Fue en San Marcos, en 1971, donde inició su carrera docente, como asociado a la Cátedra de Derecho Internacional Privado, que entonces regentaba como profesor principal don Manuel García Calderón Koechlin. El derecho internacional privado fue la disciplina jurídica que lo cautivó y la que enseñó con verdadera vocación, continuando su cultivo a lo largo de su ejercicio docente. Fue profesor de esta materia, alternativa e intermitentemente, en la Pontificia Universidad Católica del Perú y en la Universidad de San Martín de Porres. También fue profesor visitante de la misma disciplina en la Universidad de Piura, donde coincidimos en algunas oportunidades.

Pepe incursionó, asimismo, en el derecho internacional público, enseñándolo en la Universidad de San Martín de Porres, y en la Academia Diplomática llegó a dictar el curso de Introducción al Derecho. Confirmando su ancestro, fue también profesor de derecho civil en el curso de Acto Jurídico en la Universidad de San Marcos y en la Universidad de Lima - habiendo dejado en relación con esta materia algunos trabajos dispersos -, así como en el de Contratos, que dictó en San Marcos, en un reencuentro con los que habían sido sus trabajos de tesis para optar los grados de bachiller y de doctor en derecho.

Pero fue al derecho internacional privado al que le dedicó sus afanes y buena parte de su ejercicio docente en la Universidad de Lima, pues fue la materia que más concitó su interés. En la Facultad de Derecho de la Universidad de Lima regentó la cátedra, hasta que, ya enfermo, contó con la colaboración de Gonzalo García Calderón Moreyra - hijo del maestro sanmarquino-, quien lo ha sucedido. A lo largo de su ejercicio docente en nuestra universidad, se reencontró con amigos con los que había compartido inquietudes y afanes estudiantiles, como Daniel Sas -trágicamente fallecido-, Luciano Barchi Velaochaga - que continúa 
en la docencia-, Ernesto Pinto-Basurco - que está entregado a funciones diplomáticas-, Javier Barco Saravia - con quien compartió su inclinación por el derecho minero- y Oswaldo Hundskopf - su amigo y colaborador, quien lo ha sucedido en el decanato-. Con todos ellos generó un círculo de entrañable amistad.

Si bien la Universidad de Lima lo atrajo definitivamente, no lo apartó de su alma máter, la Universidad de San Marcos, a la que dedicó buena parte de su ejercicio docente, en homenaje a su padre. En la Universidad de Lima, además de la docencia, comenzó a asumir otras tareas, como las de miembro del Tribunal de Honor de Docentes y director académico del Departamento de Ciencias Jurídicas, para finalmente asumir el decanato de la Facultad de Derecho, en cuya función la artera enfermedad que lo aquejó, privó a la universidad de su brillante presencia.

Pepe fue un consultor al que, en reconocimiento de su buen tino y su clara inteligencia, se le invitaba para conformar directorios. Se desempeñó como miembro de los directorios del Banco Minero, la Empresa Nacional de Transporte Urbano, la Cruz Roja Peruana, la Empresa Minera del Perú y Minero Perú Comercial, la Empresa Minera del Centro del Perú y Electricidad de los Andes. Fue presidente del Instituto Nacional de Derecho de Minería y Petróleo, de 1992 a 1993. Durante el proceso de promoción de la inversión privada en las empresas del Estado, fue invitado a conformar diversos comités, como el de la Empresa Minera del Centro del Perú, el de la Empresa Minera del Perú, el de la Empresa Minera Tintaya y el de Bayóvar.

Como profesional de bien ganado prestigio y ciudadano con voluntad de servicio, estuvo siempre dispuesto a prestar su concurso, ya como miembro del Concejo de Lima Metropolitana, de la Junta Directiva del Colegio de Abogados de Lima y de delegaciones para asuntos de interés nacional.

Pepe fue regidor de la Municipalidad de Lima durante dos periodos: en el primero, llamado por Eduardo Orrego Villacorta, alcalde acciopopulista, de 1981 a 1983, y en el segundo, llamado por Jorge del Castillo Gálvez, alcalde aprista, de 1984 a 1986, lo que evidencia su amplitud e independencia de criterio.

En 1987 y 1988 acompañó a Raúl Ferrero Costa en su desempeño como decano del Colegio de Abogados de Lima: asumió la función de director de conferencias y la de representar al Colegio ante la entonces Federación Nacional de Colegios de Abogados. Anteriormente integró 
diversas comisiones consultivas, pues siempre era llamado debido a la lucidez y la claridad de sus conceptos.

Estas mismas cualidades lo llevaron a integrar diversas delegaciones para tratar asuntos de interés nacional: participó, entre otras, en la Conferencia sobre el Código de Conducta de las Empresas Transnacionales, en la Conferencia sobre Derecho del Mar, en la Comisión Permanente del Pacífico Sur y en la Conferencia sobre Informática Jurídica. Su prestigio como internacionalista lo llevó a participar, asimismo, en las conferencias internacionales sobre Derecho Internacional Privado y en la Comisión de las Naciones Unidas para el Derecho Mercantil Internacional, en la que entonces, siendo yo corresponsal nacional, tuve la oportunidad de estar con él en algunos eventos.

Pepe no inició su carrera profesional como abogado de bufete ni fue un abogado litigante; sin embargo, en los últimos años, formó un estudio con sus antiguos compañeros de aulas universitarias, Hernando Montoya Alberti y Alberto del Carpio, y se dedicó a la consultoría.

Su agudo razonamiento y su claridad de conceptos propiciaron que, sin ser abogado litigante, fuera invitado a participar en tribunales arbitrales, no solo como miembro del panel del Centro de Arbitraje Comercial (Cearco), de la Cámara Peruana de la Construcción, del Instituto Nacional de Derecho de Minería y Petróleo y de la Cámara de Comercio de Lima, sino también para resolver controversias en las que las partes optaban por no recurrir a las instituciones arbitrales, interviniendo así en la solución de conflictos de importante magnitud y en cuyos laudos dejó la huella de su sólida formación jurídica.

Pepe fue un hombre de hogar, y formó el suyo con Rosy Mulanovich, quien supo compartir con él la alegría de los buenos momentos y alentarlo en los momentos difíciles. Contrajeron matrimonio el 30 de mayo de 1980, y de su unión nacieron Rosa Margarita, José Augusto y Cristina, con quienes formaron un núcleo muy unido y que supo afrontar con entereza el duro trance de la artera enfermedad que lo sustrajo de su hogar.

Pepe, pues, vivió su existencia a plenitud hasta ese jueves -7 de noviembre de 2002 - que la truncó. Hoy vive en el recuerdo de sus seres queridos y de quienes fuimos honrados con su amistad. 